\title{
HEART RATE VALUES OF THE ROMANIAN WHEELCHAIR BASKETBALL PLAYERS
}

\author{
Alina Daniela MOANȚĀ ${ }^{1}$, Gabriel Iulian GHIȚESCU ${ }^{1}$, Alin Mihăiță SĂFTEL ${ }^{1 *}$, \\ Nicoleta LEONTE ${ }^{2}$

\footnotetext{
${ }^{1}$ National University of Physical Education and Sport, Faculty of Physical Education and Sport, Bucharest, Romania

2 "Politehnica" University, Department of Physical Education and Sport - Kinetotherapy, Bucharest, Romania *Corresponding author: mihaita.saftel@gmail.com
}

DOI: $10.35189 /$ iphm.icpesk.2019.22

\begin{abstract}
In Romania, the practice of wheelchair basketball has not reached the development expected by all of us, given its beneficial effects on people with motor disabilities. The research aims to bring additional information on this topic, taking into account the realities of wheelchair basketball practice in Romania, where a national competitive system for this category is missing, and therefore there is no rhythmicity of the training sessions and competitions. However, wheelchair basketball players compete in official games on various occasions, so we had the opportunity to measure their heart rates in order to determine exercise intensity during competitions. The teams were made up of players belonging to 4 clubs/associations (from Ilfov, Brașov, Prahova and Sibiu), who were connected to the Polar system for collecting data on their heart rates recorded during games. The games were played over 4 quarters of 9 minutes each, without stopping the timer. The team athletes participate in a single training session per week and occasionally in two training sessions. We mention that all players had a "fit for physical effort" medical visa. The result interpretation was done for the average value of maximum heart rate (MHR) and the maximum value of MHR. For the 6 matches played, we performed the statistical analysis by applying the t-Test, namely the Two-Sample Assuming Unequal Variances from the Excel Data Analysis Software package, of which we analysed the following: mean, standard deviation, coefficient of variation, $t$-Stat and t-Critical two-tail, alpha being 0.05.
\end{abstract}

Keywords: basketball, disabilities, heart rate.

\section{Introduction}

Wheelchair basketball is aligned with Paralympic performance sports, being the only team sport that can be played at an elite level by people with spinal cord injuries (Hedrick, Byrnes, \& Shaver, 1989). It can also be practiced by athletes with paraplegia, amputation, brittle bones and a combination of other disabilities (Săftel \& Grigore, 2018, p. 305).

In recent years, there has been an increase in the number of people with disabilities participating in various sports activities. If the first edition, in 1960, was attended by about 400 athletes from 23 countries, the last edition of the Rio 2016 Summer Paralympic Games recorded 4,350 athletes from 176 countries and 52 medals were won in 23 Paralympic sports.

Sport is recognised as an important factor in the biological and mental development and functioning of people with disabilities. The development of disability sport is a consequence of the need for better physical and mental recovery of fighters in various wars (mainly the Vietnam War, but not only) and also the need to accept a new physical label for victims of various accidents. As a result, researchers have started focusing their attention on the assessment of psychological/mental and biological characteristics (Coutts, 1990; Hutzler, 1993).

A problem in determining the biological characteristics of athletes with disabilities is the choice of instruments to measure different indicators. The difficulty arises from the differences in movement between people with disabilities and other athletes, but previous experience related to the use of various devices and tests for people without disabilities can be an important factor that should be taken into account.

The character of the effort is different for wheelchair basketball players, because they have to provide effort in order to immobilise the wheelchair.

The cardiorespiratory system of athletes with spinal cord injuries practicing different branches of sport shows unique alterations, which leads to a decline in their ability to practice physical activities compared to people who are physically fit to practice a sport or people with other types of disabilities (Nassis \& Geladas, 2002).

Several research studies (Yanci, Iturricastillo, \& Granados, 2014) conducted during wheelchair basketball competitions highlighted significant differences $(\mathrm{p}<0.05)$ in heart rate peak in the last three bouts compared to the first. According to Schmid et al. (1998), high cardiovascular stress was recorded during the competitive basketball game, indicating the presence of rapid aerobic metabolism. 
Croft, Dybrus, Lenton and Goosey-Tolfrey (2010) made a comparison between the effort provided by wheelchair basketball players and wheelchair tennis players, concluding that wheelchair basketball mostly requires high-intensity training, while wheelchair tennis training requires performing exercises with a wide-intensity range.

Although the development of the wheelchair basketball game and its various aspects are extensively examined worldwide, which is highlighted by the multitude of existing studies (Vanlandewijck, Daly, \& Theisen, 1999; Dallmeijer, Kappe, Veeger, Janssen, \& van der Woude, 1994), the research on the specific aspects of wheelchair basketball is still missing in Romania.

Currently, there are no wheelchair basketball teams in Romania that perform their activity on a regular basis, the athletes playing on the occasion of competitions organized for charity purposes or initiated by organizations dealing with the issue of people with disabilities.

In this context, our research conducted on 21 people with disabilities has certain limitations generated by the low number of subjects.

Basketball, regarded as a sport adapted to people with special needs, highlights the qualities, skills, attitudes, values and behaviours that enable subjects with disabilities to participate as active members of the society in which they live (Leonte \& Popescu, 2017, p. 27).

\section{Material and Methods}

Heart rate measurement for wheelchair basketball players was performed during a competition organized by the Motivation Foundation Romania, in partnership with the Romanian Basketball Federation and the Ministry of Youth and Sports, between 16 and 18 October 2018; actually, it was the only basketball competition held in 2018. Therefore, we think that the training level of the participating athletes was low, which influenced the test results.

The teams were made up of players belonging to 4 clubs/associations (from Ilfov, Braşov, Prahova and Sibiu), who were connected to the Polar system for collecting data on their heart rates recorded during games.

The games were played over 4 quarters of 9 minutes each, without stopping the timer. The team athletes participate in a single training session per week and occasionally in two training sessions.

Determinations were focused on maximum heart rate (MHR), which refers to the highest number of heart beats per minute that can be achieved under maximum stress. This is an individual value that depends on the subject's age, hereditary factors, physical condition and type of practiced sport, being used to express exercise intensity during training or competition.

The result interpretation was done for the average value of maximum heart rate and the maximum value of MHR.

For the 6 matches played, we performed the statistical analysis by applying the t-Test, namely the Two-Sample Assuming Unequal Variances from the Excel Data Analysis Software package, of which we analysed the following: mean, standard deviation, coefficient of variation, t-Stat and t-Critical two-tail, alpha being 0.05 .

\section{Results}

Table 1. Statistical indicators for the game between Ilfov (IF) and Sibiu (SB)

\begin{tabular}{lcc}
\hline \multicolumn{3}{c}{ t-Test: Two-Sample Assuming Unequal Variances } \\
\hline & IF & SB \\
\cline { 2 - 3 } Mean & 88.33 & 92.20 \\
Coefficient of variation & 15.29 & 16.72 \\
Observations & 6.00 & 5.00 \\
Standard deviation & 11.00 & 13.14 \\
Hypothesised mean difference & \multicolumn{2}{c}{0} \\
Df & \multicolumn{2}{c}{8} \\
t-Stat & -0.77 \\
P(T<=t) one-tail & 0.23 \\
t-Critical one-tail & 1.86 \\
P(T<=t) two-tail & 0.46 \\
t-Critical two-tail & 2.31 \\
\hline
\end{tabular}


Since the coefficient of variation has the values 15.29 and 16.27, which are below the $30 \%$ threshold, it results that both groups are homogeneous. There are no significant differences between the two teams, IF and SB, because t-Stat has the value -0.77 , being lower than t-Critical two-tail, 2.31. (Table 1)

Table 1. Statistical indicators for the game between Ilfov (IF) and Brașov (BV)

\begin{tabular}{lcc}
\hline \multicolumn{3}{c}{ t-Test: Two-Sample Assuming Unequal Variances } \\
\hline \multirow{2}{*}{ Mean } & IF & BV \\
\cline { 2 - 3 } Coefficient of variation & 90.33 & 97.20 \\
Observations & 9.13 & 15.13 \\
Standard deviation & 6.00 & 5.00 \\
Hypothesised mean difference & 6.57 & 11.59 \\
Df & \multicolumn{2}{c}{0} \\
t-Stat & 7 \\
P(T<=t) one-tail & -2.14 \\
t-Critical one-tail & 0.03 \\
P(T<=t) two-tail & 1.89 \\
t-Critical two-tail & 0.07 \\
\hline
\end{tabular}

Since the coefficient of variation has the values 9.13 and 15.13 , which are below the $30 \%$ threshold, it results that both groups are homogeneous. There are no significant differences between the two teams, IF and BV, because $\mathrm{t}$-Stat has the value -2.14 , being lower than $\mathrm{t}$-Critical two-tail, 2.36. (Table 2)

Table 2. Statistical indicators for the game between Ilfov (IF) and Prahova (PH)

\begin{tabular}{lcc}
\hline \multicolumn{3}{c}{ t-Test: Two-Sample Assuming Unequal Variances } \\
\hline & IF & PH \\
\cline { 2 - 3 } Mean & 85.83 & 89.80 \\
Coefficient of variation & 19.64 & 12.15 \\
Observations & 6 & 5 \\
Standard deviation & 13.36 & 8.84 \\
Hypothesised mean difference & \multicolumn{2}{c}{0} \\
Df & \multicolumn{2}{c}{7} \\
t-Stat & -0.67 \\
P(T<=t) one-tail & 0.26 \\
t-Critical one-tail & 1.89 \\
P(T<=t) two-tail & 0.52 \\
t-Critical two-tail & 2.36 \\
\hline
\end{tabular}

Since the coefficient of variation has the values 19.64 and 12.15 , which are below the $30 \%$ threshold, it results that both groups are homogeneous. There are no significant differences between the two teams, IF and PH, because $t-S t a t$ has the value -0.67 , being lower than t-Critical two-tail, 2.36 . (Table 3)

Table 3. Results recorded using the Polar H10 Pulse Tester for the game between Ilfov (IF) and Prahova (PH)

\begin{tabular}{|c|c|c|}
\hline IF team players & Mean\% & MHR\% \\
\hline 1 & 46 & 62 \\
\hline 2 & 66 & 81 \\
\hline 3 & 81 & 96 \\
\hline 4 & 83 & 98 \\
\hline 5 & 65 & 89 \\
\hline 6 & 67 & 89 \\
\hline
\end{tabular}




\begin{tabular}{|c|c|c|c|c|c|}
\hline \multicolumn{6}{|l|}{ PH team players } \\
\hline 1 & \multicolumn{3}{|c|}{87} & \multicolumn{2}{|l|}{97} \\
\hline 2 & \multicolumn{3}{|c|}{69} & \multicolumn{2}{|l|}{88} \\
\hline 3 & \multicolumn{3}{|c|}{69} & \multicolumn{2}{|l|}{85} \\
\hline 4 & \multicolumn{3}{|c|}{64} & \multicolumn{2}{|l|}{85} \\
\hline 5 & \multicolumn{3}{|c|}{75} & \multicolumn{2}{|l|}{94} \\
\hline Maximum - IF team & & 83 & & & 98 \\
\hline Maximum - PH team & & 87 & & & 97 \\
\hline Minimum - IF team & 46 & & 62 & & \\
\hline Minimum - PH team & 64 & & 85 & & \\
\hline Mean - IF team & & & 5.83 & & \\
\hline Mean - PH team & & & 9.80 & & \\
\hline
\end{tabular}

According to Table 4, the heart rate of players in both teams was, during the game, into the HARD intensity zone, with the means 85.83 (Ilfov team) and 89.80 (Prahova team). Analysing the MHR\%, it can be noticed that, during the game, the maximum effort zone has been reached (98 - Ilfov and 97 - Prahova).

Table 4. Results recorded using the Polar H10 Pulse Tester for the game between Ilfov (IF) and Sibiu (SB)

\begin{tabular}{|c|c|c|}
\hline IF team players & Mean\% & MHR\% \\
\hline 1 & 61 & 83 \\
\hline 2 & 57 & 78 \\
\hline 3 & 76 & 94 \\
\hline 4 & 72 & 85 \\
\hline 5 & 84 & 96 \\
\hline 6 & 82 & 94 \\
\hline \multicolumn{3}{|l|}{ SB team players } \\
\hline 1 & 71 & 85 \\
\hline 2 & 96 & 105 \\
\hline 3 & 78 & 88 \\
\hline 4 & 86 & 98 \\
\hline 5 & 62 & 85 \\
\hline Maximum - IF team & 84 & 96 \\
\hline Maximum - SB team & 96 & 105 \\
\hline Minimum - IF team & 57 & 78 \\
\hline Minimum - SB team & 62 & 85 \\
\hline Mean - IF team & & 3.33 \\
\hline Mean - SB team & & 2.20 \\
\hline
\end{tabular}

According to Table 5, the heart rate of Ilfov team players was, during the game, into the HARD intensity zone, while the heart rate of Sibiu team players was into the maximum effort zone, with the means 88.33 (Ilfov team) and 92.20 (Prahova team). Analysing the MHR\%, it can be noticed that, during the game, the maximum effort zone has been reached (96 - Ilfov), and player 2 in the Sibiu team has exceeded the maximum effort zone by 5\%, reaching $105 \%$.

Table 5. Results recorded using the Polar H10 Pulse Tester for the game between Ilfov (IF) and Braşov (BV)

\begin{tabular}{|c|c|c|}
\hline IF team players & Mean $\%$ & MHR\% \\
\hline 1 & 79 & 96 \\
\hline 2 & 74 & 86 \\
\hline 3 & 80 & 90 \\
\hline
\end{tabular}




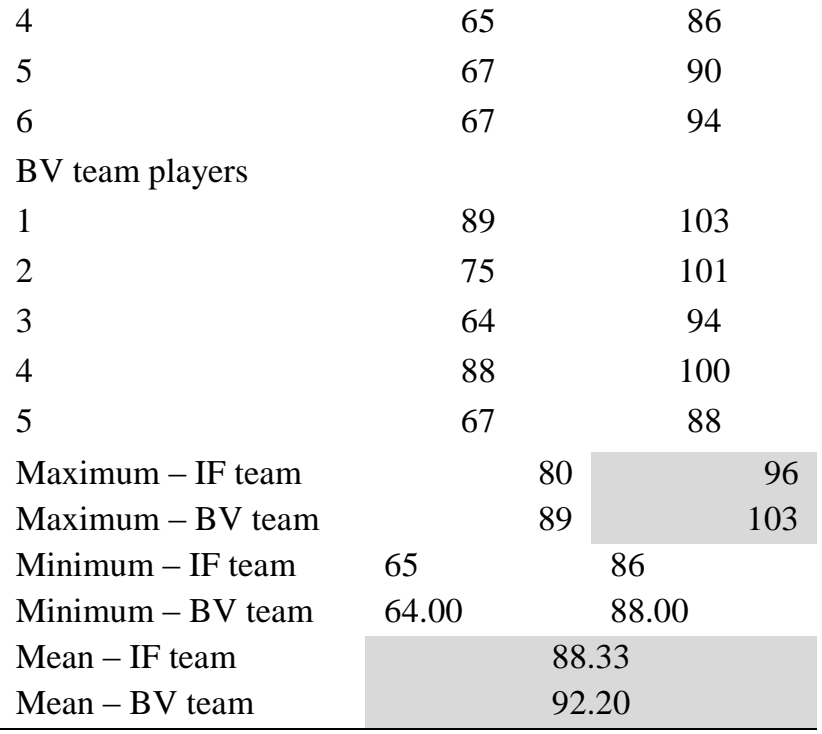

According to Table 6, the heart rate of Ilfov team players was, during the game, into the HARD intensity zone, while the heart rate of Brașov team players was into the maximum effort zone, with the means 80 (Ilfov team) and 96 (Brașov team). Analysing the MHR\%, it can be noticed that, during the game, both teams have reached the maximum effort zone (96 - Ilfov), and two players in the Brașov team have exceeded the maximum effort zone by $1 \%$ and $3 \%$, respectively, reaching indices of $101 \%$ and $103 \%$.

\section{Conclusion}

Analysing the recorded values, we can conclude that:

- the coefficient of variation has values indicating that both groups are homogeneous in terms of heart rate value, the teams falling into the maximum effort zone during games; from this point of view, we think that the competitive effort has exerted maximum or almost maximum demands on the respiratory and muscular systems; such effort is recommended for a shorter period than 5 minutes;

- $\quad$ since the results are not significantly different from the physical point of view, we can say that the difference in results is due to the technical, tactical and psychological training of Ilfov team players, actually the winners of the competition;

- the scores recorded by 3 players out of the 21 indicate that they have exceeded the maximum effort zone, which can be translated by their maladjustment to the effort provided.

\section{References}

Coutts, K. (1990). Peak oxygen uptake of elite wheelchair athletes. Adapted Physical Activity Quarterly, 7(1), 6266. https://doi.org/10.1123/apaq.7.1.62

Croft, L., Dybrus, S., Lenton, J., \& Goosey-Tolfrey, V. (2010). A comparison of the physiological demands of wheelchair basketball and wheelchair tennis. International Journal of Sports Physiology and Performance, 5(3), 301-315. https://doi.org/10.1123/ijspp.5.3.301

Dallmeijer. A. J., Kappe, Y. J., Veeger, D. H. E., Janssen, T. W., \& van der Woude, L. H. (1994). Anaerobic power output and propulsion technique in spinal cord injured subjects during wheelchair ergometry. Journal of Rehabilitation Research and Development, 31(2), 120-128. Retrieved from https://www.rehab.research.va.gov/jour/94/31/2/pdf/dallmeijer.pdf

Leonte, N., \& Popescu, O. (2017). Prevenirea și corectarea atitudinilor corporale deficitare prin mijloacele jocului de baschet [Prevention and correction of deficient bodily attitudes through the means of the basketball game]. București: Discobolul.

Hedrick, B., Byrnes, D., \& Shaver, L. (1989). Wheelchair basketball. Washington: Paralyzed Veterans of America.

Hutzler, Y. (1993). Physical performance of elite wheelchair basketball players in arm cranking ergometry and in selected wheeling tasks. Paraplegia, 31(4), 255-261. https://doi.org/10.1038/sc.1993.45 
Nassis, G. P., \& Geladas, N. D. (2002). Cardiac output decline in prolonged dynamic exercise is affected by the exercise mode. European Journal of Physiology, 445(3), 398-404. https://doi.org/10.1007/s00424-002-0935-5

Schmid, A., Huonker, M., Stober, P., Barturen, J. M., Schmidt-Trucksäss, A., Dürr, H., ... Keul, J. (1998). Physical performance and cardiovascular and metabolic adaptation of elite female wheelchair basketball players in wheelchair ergometry and in competition. American Journal of Physical Medicine \& Rehabilitation, 77(6), 527-533. Retrieved from https://www.ncbi.nlm.nih.gov/pubmed/9862541

Săftel, M. A., \& Grigore, V. (2018). Comparative study of speed level in wheelchair basketball from different county. In The European Proceedings of Social \& Behavioural Sciences (Vol. XXXVI - ICPESK 2017, pp. 304-309). http://dx.doi.org/10.15405/epsbs.2018.03.40

Vanlandewijck, Y., Daly, D., \& Theisen, D. (1999). Field test evaluation of aerobic, anaerobic, and wheelchair basketball skill performances. International Journal of Sports Medicine, 20(8), 548-554. https://doi.org/10.1055/s-1999-9465

Yanci, J., Iturricastillo, A., \& Granados, C. (2014). Heart rate and body temperature response of wheelchair basketball players in small-sided games. International Journal of Performance Analysis in Sport, 14(2), 535544. https://doi.org/10.1080/24748668.2014.11868741 